\title{
Editorial \\ Breast cancer surface receptors predict risk for developing brain metastasis and subsequent prognosis
}

\author{
Jai Grewal ${ }^{1}$ and Santosh Kesari ${ }^{2}$
}

\begin{abstract}
'Long Island Center for Brain and Spine Tumors 600 Northern Blvd, suite 113, Great Neck, NY 11021, 516-478-0010, USA
${ }^{2}$ Center for Neuro-Oncology, Dana-Farber/Brigham and Women's Cancer Center and Division of Cancer Neurology, Department of Neurology, Brigham and Women's Hospital, Harvard Medical School, Boston, Massachusetts 02115, USA
\end{abstract}

Corresponding author: Santosh Kesari, skesari@partners.org

Published: 14 March 2008

Breast Cancer Research 2008, 10:104 (doi:10.1186/bcr1868)

This article is online at http://breast-cancer-research.com/content/10/2/104

(c) 2008 BioMed Central Ltd

See related research article by Nam et al., http://breast-cancer-research.com/content/10/1/R20

\begin{abstract}
Determining the status of breast cancer surface receptors (estrogen receptor, progesterone receptor, HER2/neu) has become routine in the care of patients with this disease and has proven to be helpful in guiding treatment. For this reason, breast cancer has become a model for molecularly guided therapy in solid tumors. Emerging data support that these receptors are associated with risk for developing brain metastases. Additionally, once brain metastases have occurred these receptors may also correlate with prognosis.
\end{abstract}

The retrospective analysis presented by Nam and coworkers [1] is consistent with prior data suggesting increased risk for brain metastases and shortened survival in patients with brain metastases when there is a lack of surface hormone receptors (estrogen receptor [ER]-negative/progesterone receptor $[\mathrm{PR}]$-negative status). This study goes one step further and attempts to correlate the outcomes of brain metastasis with intrinsic breast cancer subtypes, using the receptor combinations as a surrogate marker for the subtypes defined by gene expression microarrays. There appears to be a higher proportion of human epidermal growth factor receptor (HER)2-positive/ER-negative and triple-negative disease among patients with brain metastases. HER2positive status did not appear to increase the risk for brain metastasis, as described in other studies [2,3]. There are conflicting data in the literature on the significance of HER2 with regard to brain metastases in breast cancer, and several unanswered questions remain. Does HER2 positivity affect risk for brain metastasis? Does HER2 positivity affect survival among breast cancer patients with brain metastases? Finally, do these correlations with parenchymal brain metastases extend to leptomeningeal disease (LMD)?
Regarding the first question, there are conflicting findings in the literature on the correlation between HER2 status and the risk for brain metastasis. HER2-positive breast cancer has been associated with increased risk for brain metastases in some studies [2,3], but others found no significant association $[1,4]$. In considering the possibility that HER2positive status may increase the risk for brain metastasis, several confounding issues must be considered in the trastuzumab era. It has been suggested that trastuzumab itself may be related to the increased risk for brain metastasis [5]. However, trastuzumab has also resulted in improved survival in HER2-positive metastatic breast cancer. Because brain metastasis typically occurs in late breast cancer, longer survival may be the confounding factor in HER2-positive patients who develop brain metastases and receive trastuzumab. Several recent studies suggested that triplenegative breast cancer results in poorer survival than does HER2-positive/ER-negative status in the setting of residual disease $[6,7]$.

The second issue concerns the prognostic value of HER2 once brain metastasis has occurred. In the era of trastuzumab, outcomes in HER2-positive brain metastasis appear to be more favorable, because these patients can been treated with trastuzumab, which results in prolonged survival. It is believed that prolonged survival in patients with brain metastasis who are HER2 positive is a result of improved extracranial disease control rather than a direct effect on the brain metastases. Median survival was significantly longer among patients who received trastuzumab after the onset of brain metastasis in the study reported by Nam and coworkers [1] (12.8 months versus 4.0 months).

$\mathrm{ER}=$ estrogen receptor; $\mathrm{HER}=$ human epidermal growth factor receptor; $\mathrm{LMD}=$ leptomeningeal disease; $\mathrm{PR}=$ progesterone receptor. 
Although overall prognosis may be better in HER2-positive brain metastases, the most important reason for failure of trastuzumab to control these metastases may be the inability of this antibody to cross the blood-brain barrier adequately [8]. However, the trastuzumab cerebrospinal fluid/plasma ratio appears to increase in the setting of radiation therapy and LMD [9], with responses observed [10]. Alternatively, could the brain metastases simply lose expression of the HER2 receptor? Although discordance of HER2 staining between primary and metastatic tissues has been described for other cancers, Fuchs and coworkers [11] reported that the overall rate of concordance in HER2 status between brain metastases and the primary breast cancer was $97 \%$ in 29 patients evaluated. It may be necessary to analyze larger datasets before the association between HER2, brain metastases, and trastuzumab can be clarified.

Finally, Nam and coworkers [1] found LMD to be the factor most associated with a poor outcome. Given the significance of this type of metastasis, what do we know about the correlation between receptor status and the risk and prognosis of LMD? LMD in breast cancer is unique compared with LMD in other solid tumor histologies, in that a subset of patients can have relatively prolonged survival. Does receptor status correlate with LMD in the same way as it might for parenchymal brain metastases? There is a paucity of data addressing this specific issue. A small retrospective study of breast cancer patients with LMD suggested a trend toward an increased proportion of HER2-positive/ERnegative breast cancer among patients with LMD than among patients without LMD [12]. This is another area in which additional research is greatly needed.

The report by Nam and coworkers [1] adds further evidence that a more detailed molecular classification of disease (longitudinally in individual patients) may lead to fruitful hypothesis-generating data, which will help us to further dissect the molecular mechanisms involved in the metastatic process and eventually lead to rational treatment strategies to prevent or treat metastasis.

\section{Competing interests}

The authors declare that they have no competing interests.

\section{References}

1. Nam B-H, Kim SY, Han HS, Kwon Y, Lee KS, Kim TH, Ro J: Breast cancer subtypes and survival in patients with brain metastases. Breast Cancer Res 2008, 10:R20.

2. Hicks DG, Short SM, Prescott NL, Tarr SM, Coleman KA, Yoder BJ, Crowe JP, Choueiri TK, Dawson AE, Budd GT, Tubbs RR, Casey G, Weil RJ: Breast cancers with brain metastases are more likely to be estrogen receptor negative, express the basal cytokeratin CK5/6, and overexpress HER2 or EGFR. Am J Surg Pathol 2006, 30:1097-1104.

3. Miller KD, Weathers T, Haney LG, Timmerman R, Dickler M, Shen J, Sledge GW Jr: Occult central nervous system involvement in patients with metastatic breast cancer: prevalence, predictive factors and impact on overall survival. Ann Oncol 2003, 14: 1072-1077.
4. Tham YL, Sexton K, Kramer R, Hilsenbeck S, Elledge R: Primary breast cancer phenotypes associated with propensity for central nervous system metastases. Cancer 2006, 107:696704.

5. Weitzen R, Zach L, Kaufman B, Tichler T, Rath P, Pfeffer R: High incidence of brain metastasis (BM) in patients on trastuzumab $(\mathrm{H})$ for advanced breast cancer [abstract]. Proc Am Soc Clin Oncol 2002, 21:1936.

6. Carey LA, Dees EC, Sawyer L, Gatti L, Moore DT, Collichio F, Ollila DW, Sartor Cl, Graham ML, Perou CM: The triple negative paradox: primary tumor chemosensitivity of breast cancer subtypes. Clin Cancer Res 2007, 13:2329-2334.

7. Liedtke C, Mazouni C, Hess KR, André F, Tordai A, Mejia JA, Symmans WF, Gonzalez-Angulo AM, Hennessy B, Green M, Cristofanilli M, Hortobagyi GN, Pusztai L: Response to neoadjuvant therapy and long-term survival in patients with triplenegative breast cancer. J Clin Oncol 2008 [Epub ahead of print].

8. Pestalozzi BC, Brignoli S: Trastuzumab in CSF. J Clin Oncol 2000, 18:2349-2351.

9. Stemmler HJ, Schmitt M, Willems A, Bernhard H, Harbeck N, Heinemann V: Ratio of trastuzumab levels in serum and cerebrospinal fluid is altered in HER2-positive breast cancer patients with brain metastases and impairment of blood-brain barrier. Anticancer Drugs 2007, 18:23-28.

10. Baculi RH, Suki S, Nisbett J, Leeds N, Groves M: Meningeal carcinomatosis from breast carcinoma responsive to trastuzumab. J Clin Oncol 2001, 19:3297-3298.

11. Fuchs IB, Loebbecke M, Buhler H, Stoltenburg-Didinger $G$, Heine B, Lichtenegger W, Schaller G: HER2 in brain metastases: issues of concordance, survival, and treatment. J Clin Oncol 2002, 20:4130-4133.

12. Grewal J, Groves MD, Bekele BN, Yung WA: The role of HER2/neu, estrogen, and progesterone receptor status in the risk and survival of breast cancer leptomeningeal metastasis (2007 ASCO Annual Meeting Proceedings Part I) [abstract]. J Clin Oncol 2007, 25:11512. 